\title{
Past and future plant diversity of a coastal wetland driven by soil subsidence and climate change
}

\author{
Han F. van Dobben • Pieter A. Slim
}

Received: 5 January 2010 / Accepted: 16 May 2011 / Published online: 21 June 2011

(C) The Author(s) 2011. This article is published with open access at Springerlink.com

\begin{abstract}
On the island of Ameland (The Netherlands), natural gas has been extracted from a dune and salt marsh natural area since 1986. This has caused a soil subsidence of c. 1-25 cm, which can be used as a model to infer effects of future sea level rise. The aims of our study were (a) to relate the changes in the vegetation, and more specifically, in plant diversity, during the extraction period to soil subsidence and weather fluctuations, and (b) to use these relations to predict future changes due to the combination of ongoing soil subsidence and climate change. We characterised climate change as increases in mean sea level, storm frequency and net precipitation. Simultaneous observations were made of vegetation composition, elevation, soil chemistry, net precipitation, groundwater level, and flooding frequency over the period 1986-2001. By using multiple regression the changes in the vegetation could be decomposed into (1) an oscillatory component due to fluctuations in net precipitation, (2) an oscillatory component due to incidental flooding, (3) a monotonous component due to soil subsidence, and (4) a monotonous component not related to any measured variable but probably due to eutrophication. The changes were generally small during the observation period, but the regression model predicts large changes by the year 2100 that are almost exclusively due to sea level rise. However, although sea level rise is expected to cause a loss of species, this does not necessarily lead to a loss of conservancy value.
\end{abstract}

Electronic supplementary material The online version of this article (doi:10.1007/s10584-011-0118-5) contains supplementary material, which is available to authorized users.

H. F. van Dobben $(\varangle)$. P. A. Slim

Alterra, Wageningen UR, POB 47, 6700AA Wageningen, The Netherlands

e-mail: han.vandobben@wur.nl 


\section{Introduction}

In coastal environments water level and salt influence are assumed to be key factors for the vegetation (Dijkema and Wolff 1983), and these are in turn determined by the combination of elevation and weather conditions. Storm surges will lead to salinization, while high precipitation will cause desalinization. As the influence of both seawater and fresh water is determined by the elevation relative to the sea level, soil subsidence, if it occurs in a coastal area, can be used to mimic sea level rise. We conducted a case study on the island of Ameland $\left(53^{\circ} 27^{\prime} \mathrm{N} 5^{\circ} 53^{\prime} \mathrm{E}\right)$, The Netherlands (see Electronic Supplementary Material 1), where near shore extraction of natural gas caused compaction of geological layers at $2-3 \mathrm{~km}$ depth, resulting in a progressive soil subsidence of up to $25 \mathrm{~cm}$ over a 15-year period (Eysink et al. 2000). This amount of soil subsidence is in the same order of magnitude as the sea level rise expected by 2100 (c. $44 \mathrm{~cm}$, Church et al. 2001), and can thus be used to infer future changes in the vegetation.

Ameland is part of the chain of barrier islands that are located along the coasts of The Netherlands, Germany and Denmark, and that separates the Wadden Sea from the North Sea. Most of these islands consist of a sandy dune landscape along the North Sea coast, and a clayey salt marsh landscape along the Wadden Sea coast (Van Dieren 1934; Dijkema and Wolff 1983; Ketner-Oostra and Sýkora 2000). The eastern part of Ameland, where our study was conducted, is open to the sea and had little human influence until extraction of natural gas started in 1986. At the start of the gas extraction a monitoring program was set up because there was a concern for largescale drowning and salinisation of dune vegetation. However, while the monitoring program was running it was progressively realised that the ultimate effect would be determined by the combination of soil subsidence and sea level rise. Therefore the present study concentrates on (1) an assessment of the effects of soil subsidence, and (2) a prediction of the effects of continuing soil subsidence combined with effects of climate change.

We monitored the species composition of the vegetation at 3-year intervals over the first 15 years of gas extraction, using permanent plots. To explain the observed changes we modelled the vegetation as a resultant of net precipitation, sea level regime, soil chemistry, the elevation at the start of the gas extraction and the soil subsidence that occurred after that. Next, we used this model to assess future changes assuming a scenario derived from IPCC predictions (Church et al. 2001). Besides predicting the species composition itself, we also attempted to estimate past and future changes in biodiversity, which we characterised by two measures: the number of species per plot, and the 'Compound Conservancy Value' (CCV, Wamelink et al. 2003; Van Dobben and Wamelink 2009) which is based on the combination of regional rarity and decline per species.

The aims of our study were (a) to verify the hypothesis that the observed vegetation changes are at least partly due to soil subsidence, and (b) to use the observed relation between elevation, weather conditions and the state of the vegetation to predict future changes in the vegetation, and in particular its diversity, taking account of both the expected soil subsidence until the end of the gas extraction, and the expected climate change until 2100. 


\section{Material and methods}

\subsection{Vegetation data}

Fifty-six permanent plots $2 \times 2 \mathrm{~m}$ in size were laid out in 1986, before the start of the gas extraction, and 10 additional plots were laid out in 1989 to get a better coverage of the abiotic conditions present in the area (see Electronic Supplementary Material 1 for the location of the plots, together with contour lines of soil subsidence). The plots were arranged in five transects, which cover a wide range of vegetation types in lower parts of the dry dunes, (periodical) fresh water pools, wet dune slack, and higher parts of the salt marsh. However, lower salt marshes, where soil subsidence is partly compensated by sedimentation (Dijkema et al. 2005), were not included in this study. Besides covering a range of abiotic conditions, the plots also cover the whole range of subsidence values, from c. $25 \mathrm{~cm}$ in 2001 near the extraction point, down to c. $1 \mathrm{~cm}$ at $5 \mathrm{~km}$ away from the extraction point (Electronic Supplementary Material 1). Although the plots fully cover the abiotic variation (except high dunes and lower salt marsh) and variation in soil subsidence in the area, we do not claim that the results of individual plots can be spatially generalised. This would call for a different layout of the plots, as is pointed out by Slim et al. (2005).

The vegetation of the plots was sampled at 3-year intervals between 1986 and 2001 , by visually estimating the percentage cover for vascular species, bryophytes and lichens. All bryophytes and lichens, and also vascular species that were not readily recognisable in the field, were collected for later identification.

\subsection{Abiotic data}

The phreatic level (PLS) was determined in piezometers that were installed in the autumn of 1986. One piezometer with a filter depth of c. $1.2 \mathrm{~m}$ was installed for each group of 1-10 nearby plots (19 piezometers in total). Water depths in these piezometers were recorded yearly on April, 26-28.

The elevation $(Z)$ of all plots and all piezometers was determined relative to the Dutch standard reference level (Amsterdam Zero) by RTK-DGPS in 2001. Soil subsidence was modelled as a non-linear function of $\mathrm{X}$ and $\mathrm{Y}$ coordinate and time, parameterised on the basis of precision geodetic measurements carried out at regular intervals during the period 1986-2001 (see Electronic Supplementary Material 2 for a description of the model). The elevation of the plots over time was calculated on the basis of the measured elevation in 2001 and the modelled soil subsidence. The water levels in the plots were calculated from the difference in elevation between the piezometers and the plots' soil surface in 2001, assuming a horizontal phreatic plane, and a difference in elevation between the piezometers and the plots that is constant over time.

Net precipitation $\left(\mathrm{P}_{\text {net }}\right)$ was estimated from rainfall measured at a weather station c. $10 \mathrm{~km}$ West of the study area, and evaporation at the nearest weather station where data were available (at c. 10-100 km). The vegetation in a given year was related to precipitation minus evaporation summed over a period from November in the previous year up to April in that year. 
Flooding frequency (FF) was calculated per calendar year for each plot. This was done on the basis of continuous sea level recording in the island's harbour, and the plot's elevation in each year, taking account of the fact that some of the low-lying plots were located behind dunes and thus inaccessible for seawater. As previous studies (e.g. Dijkema et al. 2007) showed a considerable time-lag in the vegetation's response to flooding we used the flooding frequencies summed over the 2 years preceding the vegetation record as a predictor in the statistical analysis. The yearly variation in sea level regime was characterised by the flooding frequency at $2 \mathrm{~m}$ above Amsterdam Zero $\left(\mathrm{FF}_{2}\right)$; at this level flooding takes place c. 3-30 times per year. Also for this variable the value entered into the statistical analysis is the flooding frequency summed over the 2 years preceding the vegetation record.

Soil chemistry was determined in samples taken in 1995. Twenty-five corings with a diameter of $2 \mathrm{~cm}$ were taken to a depth of $25 \mathrm{~cm}$ at all sides, at a distance of c. $10 \mathrm{~cm}$ outside each plot. Litter was removed, and the samples were air dried and taken to the laboratory. Total $\mathrm{N}$ and $\mathrm{P}$ were determined colourimetrically after destruction with sulphuric-salicylic acid. $\mathrm{Na}, \mathrm{K}$ and $\mathrm{Ca}$ were determined by AAS after destruction in Fleischmann acid. Chloride was determined by Chlor$\mathrm{O}-\mathrm{Counter}$ after water extraction at $20^{\circ}$. $\mathrm{pH}$ was determined potentiometrically in water extract.

\subsection{Statistical methods}

All abiotic data were checked for non-normality and outliers. Flooding frequency and all chemical data except $\mathrm{pH}$ were $(\ln (\mathrm{X}-\min (\mathrm{X})+1)$ transformed to achieve normality. Cover percentages per species were $\ln (\mathrm{X}+1)$ transformed. Other data were left untransformed.

The variability of the vegetation in space was characterised by making a local typology using the program TWINSPAN (Hill 1979). Detrended Correspondence Analysis (DCA), carried out by the ordination program CANOCO (Ter Braak and Smilauer 2002), was used to characterise the change in the vegetation over time; and its canonical form (CCA) was used to characterise the effect of the abiotic variables on the vegetation. The stepwise selection procedure and significance test based on permutation implemented in CANOCO was used to evaluate the importance of each abiotic variable. In each step the term was added to the model that yielded the largest increase in fit, subject to the constraint that its correlation with all terms already in the model should be lower than 0.6 in absolute value, until no more terms remained whose effect was significant ( $\mathrm{P}<0.001$ at 999 permutations, cf. Jongman et al. 1995).

The state of the vegetation was quantified by three descriptors: the 'sample scores' derived from DCA (denoted as AX1, AX2 etc. for the consecutive axes), the 'Compound Conservancy Value' (CCV) and the number of species per plot (Nspec). The CCV was computed according to Hertog and Rijken (1996) with a modification described in Sanders et al. (2004). A summary of the method is given by Wamelink et al. (2003). Essentially, this method assigns a value to each species according to its regional rarity and rate of decline (the criteria of the Red List, IUCN 2001), and adds the values per species to a value per plot. This indicator is used because it gives a better representation of field ecologists' valuation of the vegetation, and is more sensitive to environmental changes than traditional diversity measures like the Simpson index (Huston 1994). 
Standard linear techniques (linear regression and REML; Robinson 1987) were used to relate the vegetation descriptors to the abiotic variables and their change over time. All computations (except ordination) were carried out by the program GENSTAT release 11 (Payne et al. 2008).

In our statistical analysis we considered the state of the vegetation at any point in time as the sum of four components: (1) an oscillatory component, due to fluctuations in net precipitation; (2) an oscillatory component, due to fluctuations in sea level regime; and (3) a linear component, due to soil subsidence, and (4) a static component, due to soil chemistry and elevation at the start of the monitoring (Fig. 1). We performed a check on the statistical significance of the effect of weather conditions $\left(\mathrm{P}_{\text {net }}\right.$ and $\left.\mathrm{FF}_{2}\right)$ plus elevation on PLS and FF, respectively; and of the effect of PLS and $\mathrm{FF}_{2}$ on the vegetation descriptors (i.e., the drawn arrows in Fig. 1). Next, we skipped the intermediate step though PLS and FF, and directly modelled the vegetation as a resultant of weather conditions and elevation, and used the resulting regression equations to back predict the rate of soil subsidence. The back predicted rate was compared to the measured rate, and if these two values corresponded, it was judged likely that the change in that vegetation descriptor was caused by soil subsidence. In a more formal way the method can be described as follows:

The change in each vegetation descriptor $Y$ was modelled as a linear function of an abiotic condition $X$ that varies over time:

$$
Y_{\mathrm{t}}=a_{0}+a_{1} X_{1, \mathrm{t}}+f(\text { time-independent variables })+\varepsilon
$$

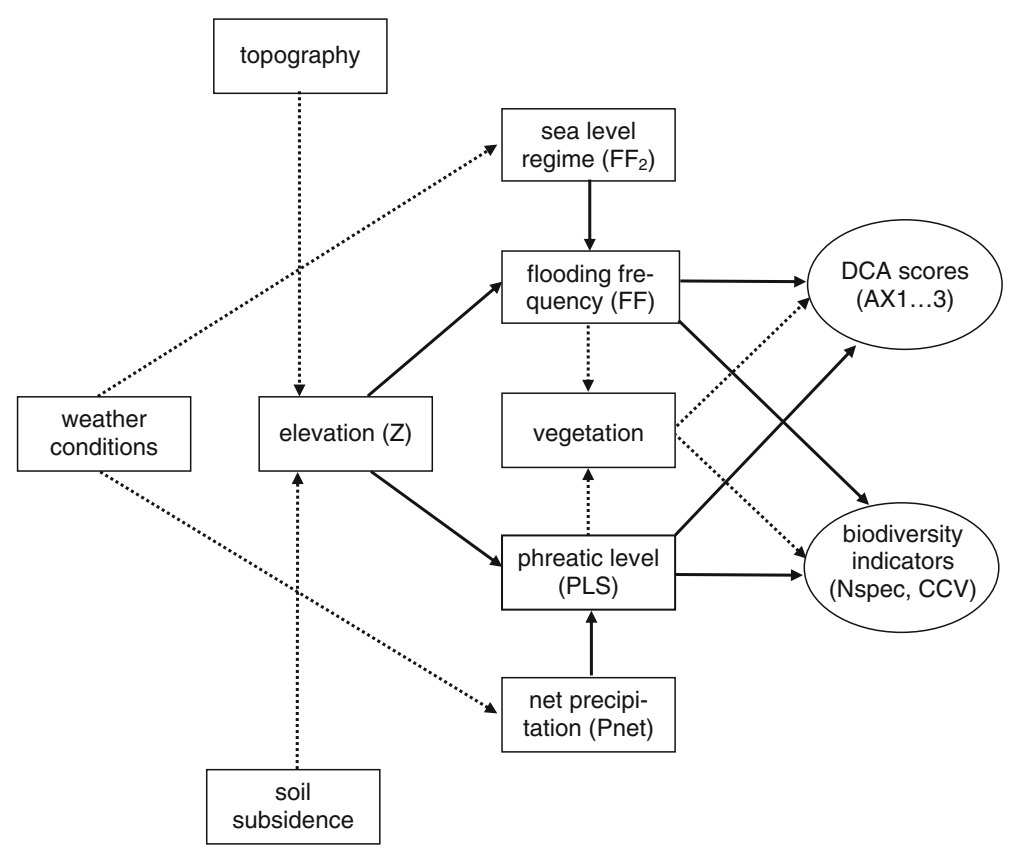

Fig. 1 Conceptual model used to evaluate the effects of soil subsidence on the vegetation. Relations indicated by drawn arrows have been tested for their statistical significance 
where $Y$ : vegetation descriptor (DCA scores, $\mathrm{CCV}$ and number of species), $X_{1}$ : either phreatic level or flooding frequency, $a_{\mathrm{n}}$ : regression coefficient, $\mathrm{t}$ : in year $\mathrm{t}, \varepsilon$ : error.

Note that in Eq. 1 the implicit assumption is made that there is no time lag in the response of the vegetation. However, a constant and known time lag can be accounted for by replacing $\mathrm{t}$ by (t-time lag). As explained above this has been done for the effect of flooding frequency.

The abiotic variables $X_{1}$ that are under the influence of elevation (phreatic level and flooding frequency) were modelled as functions of elevation and weather conditions:

$$
X_{1, t}=b_{0}+b_{1} Z_{t}+b_{2} X_{2, t}+\varepsilon
$$

where $Z$ : elevation, $X_{2}$ : either net precipitation or flooding frequency at $2 \mathrm{~m}$ height, $b_{\mathrm{n}}:$ regression coefficient.

Equations 1 and 2 can be combined into

$$
Y_{t}=c_{0}+c_{1} Z_{t}+c_{3} X_{2, t}+f(\text { time-independent variables })+\varepsilon
$$

where $c_{0}=a_{0}+a_{1} b_{0}, c_{1}=a_{1} b_{1}, c_{3}=a_{1} b_{2}$

Next, the subsidence of each plot was modelled as a linear function of its distance to the gas extraction point, and time. To do this, the soil subsidence area was assumed to be circular (cf. Electronic Supplementary Material 1), and with a subsidence that linearly increases with time and with distance from the circumference of the circle. The radius of the circle was determined by extrapolation:

$$
Z_{t}-Z_{0}=d_{0}+d_{1} D+\varepsilon
$$

where $Z$ : elevation $\left(Z_{0}\right.$, in 1986 ; and $Z_{\mathrm{t}}$, in 2001), $D$ : distance to the gas extraction point, $d_{\mathrm{n}}$ : regression coefficient. From Eq. 4 it follows that

$$
D_{0} \approx-d_{0} / d_{1}
$$

where $D_{0}$ : radius of the soil subsidence area.

Considering soil subsidence as linear in space and time, it follows that

$$
Z_{t}=Z_{0}+v\left(J-J_{0}\right)\left(D_{0}-D\right)+\varepsilon
$$

where $Z$ : elevation $\left(Z_{0}\right.$, in $1986 ; Z_{1}$, in 1987 ; etc. $), J$ : year number $\left(J_{0}=1986\right), D$ : distance to the gas extraction point ( $D_{0}=$ radius of the soil subsidence area), $v$ : soil subsidence rate (i.e., subsidence per year per meter distance from the edge of the soil subsidence area).

The error of this linear subsidence model was checked against the non-linear model described in Electronic Supplementary Material 2. The outcomes of both models appeared to be very similar $(\mathrm{R}=0.998)$. 
Now, Eqs. 3 and 6 can be combined into

$$
\begin{aligned}
Y_{t}= & c_{0}+c_{1} Z_{0}+c_{1} v\left(J-J_{0}\right)\left(D_{0}-D\right)+c_{3} X_{2, t} \\
& +f(\text { time-independent variables })+\varepsilon
\end{aligned}
$$

In a multiple regression, $c_{1} v$ can be estimated as the parameter $c_{2}$ of the term $\left(J-J_{0}\right)\left(D_{0}-D\right)$. Therefore,

$$
c_{2}=c_{1} v \text { or } v_{\text {est }}=c_{2} / c_{1}
$$

where $v_{\text {est }}$ : soil subsidence rate estimated on the basis of the vegetation change and the relation between vegetation and the elevation of the plot in 1986 (the 'back predicted' value).

Equations 6 and 8 yield independent estimates of $v$ (cf. Van Dobben and Ter Braak 1998). If the change in $Y$ over the years is caused by soil subsidence, these two estimates should have values that are not significantly different from each other. Therefore, the $99 \%$ confidence interval of $v_{\text {est }}$ was determined by using Fieller's theorem (cf. Finney 1971 p. 78) and compared to the value of $v$ from Eq. 6. If the value of $v$ (the 'true' value) was within the $99 \%$ confidence interval of $v_{\text {est }}$ it was considered likely that the change in $Y$ was due to soil subsidence.

The above method was applied twice, namely for $X_{2}=$ net precipitation and for $X_{2}=$ flooding frequency at $2 \mathrm{~m}$. In the latter case that analysis was restricted to the plots that were accessible for seawater.

\subsection{Prediction of future effects}

In order to predict the effect of continuing soil subsidence under scenarios of changing sea level, storm frequency and precipitation, Eq. 1 was expanded into:

$$
Y_{t}=a_{0}+a_{1} L_{t}+a_{2} F_{t}+\Sigma_{i=3 \ldots n}\left(a_{i} S_{i}\right)+\varepsilon
$$

where $Y$ : vegetation descriptors as in Eq. $1, a_{\mathrm{n}}$ : regression coefficient, $L$ : phreatic level, $F$ : flooding frequency, $S_{\mathrm{i}}$ : soil properties.

Equation 9 was fitted using all data in both space and time. Soil properties $S_{\mathrm{i}}$ were selected for which $a_{\mathrm{i}}$ was significantly $(P<0.05)$ different from 0 . Next, Eq. 2 was fitted, again using all data in both space and time, which yielded two sets of the regression parameters $b_{\mathrm{n}}$ (for net precipitation and flooding frequency, respectively). New values of $L$ and $F$ were estimated from Eq. 2, using the parameters determined in the previous step and scenarios with values for mean sea level, net precipitation and storm frequency derived from IPCC data (Church et al. 2001).

Two scenario were used, one for 2020 (the expected end of the gas extraction) and one for 2100 (the IPCC time horizon). The scenarios assume linear increases of mean sea level, storm frequency (characterised as the flooding frequency at our reference level of $2 \mathrm{~m}$ ) and net precipitation after 2001, to reach the present day value plus $44 \mathrm{~cm}$ (mean sea level), twice the present day value (flooding frequency at the reference level), and the present day value plus $10 \%$ (net precipitation) by 2100. These values are based on Church et al. (2001) for mean sea level and net precipitation, and on Lowe et al. (2001) and Senior et al. (2002) for storm frequency. 
Soil subsidence is assumed to increase linearly after 2001 to reach a maximum value of $33 \mathrm{~cm}$ at the deepest point by 2020 (Marquenie and Doornhof 2005) and remain constant thereafter. Values for $Z$ in Eq. 2 were obtained by subtracting the expected values for additional soil subsidence and mean sea level rise from the elevation in 2001. The expected values for $L$ and $F$, and the regression parameters $a_{1 \ldots n}$ determined previously were put into Eq. 9 to compute an expected value of $Y$ under each scenario. A check was performed to ascertain that the expected values of $Y$ do not fall outside the range of the calibration set. In our scenarios we hypothesise that hydrological changes (including changes in salinity) are the components of climate that have the major impact on coastal systems, and we did not take temperature rise into consideration. Although temperature rise might cause the invasion of a number of southern species this effect is outside the scope of the present study, also because it would call for a totally different type of model.

\section{Results}

\subsection{Variation of the vegetation in space and time}

The first three divisions of the TWINSPAN classification were used to make a local typology based on all plot/year combinations. The eight types resulting from this classification were reduced to six by merging three of the types in the dry dunes that were judged too similar to justify a separate treatment. The final types are: (1) sandy salt marsh, transition between salt marsh and dune, (2) clayey salt marsh, (3) dune slacks and pools, incl. their shores, (4) dune shrub, (5) dune heath, (6) 'grey' dunes i.e. sparsely vegetated, dry and sandy dunes. A description of these types, together with their mean abiotic values and a list of the most common species are given in Electronic Supplementary Material 3. Most plots appeared to belong to a single type throughout the observation period, and those that did not were assigned to the type to which they belonged most of the time.

Figure 2 is the biplot resulting from DCA, using the observations in all plots and at all points in time. The sample scores (Figs. 2a and c) have been summarised as average values for each combination of vegetation type and observation year. An ecological interpretation of the DCA axes was based on (1) the relation of the axes with the 'Ellenberg' ecological indicator values (Ellenberg et al. 1991; Siebel 1993; see Electronic Supplementary Material 4 for details), (2) the species' position in Figs. $2 b$ and $d$ and their ecology inferred from e.g. from Oberdorfer (1979), Weeda et al. (1985-1994) or Van der Meijden (1990), and (3) the relation of the axes with measured abiotic variables. The variables with a significant $(\mathrm{P}<0.001)$ effect were selected in a separate CCA analysis (details not shown); these appeared to be PLS, $\mathrm{FF}$, and the soil chemical variables $\mathrm{N}_{\text {tot }}, \mathrm{K}, \mathrm{Ca}$ and $\mathrm{pH}$. Their relation with the vegetation is graphically shown in Fig. 3 and described in more detail in Electronic Supplementary Material 5. The first axis mainly represents the wet-dry gradient, the second axis the gradient from seawater influence to fresh water influence; and the third axis the gradient from a low-productive (open) vegetation of nutrient-poor conditions to a high-productive (dense) vegetation of nutrient-rich conditions. The fourth axis has little correlation with the Ellenberg scores and neither is there an 

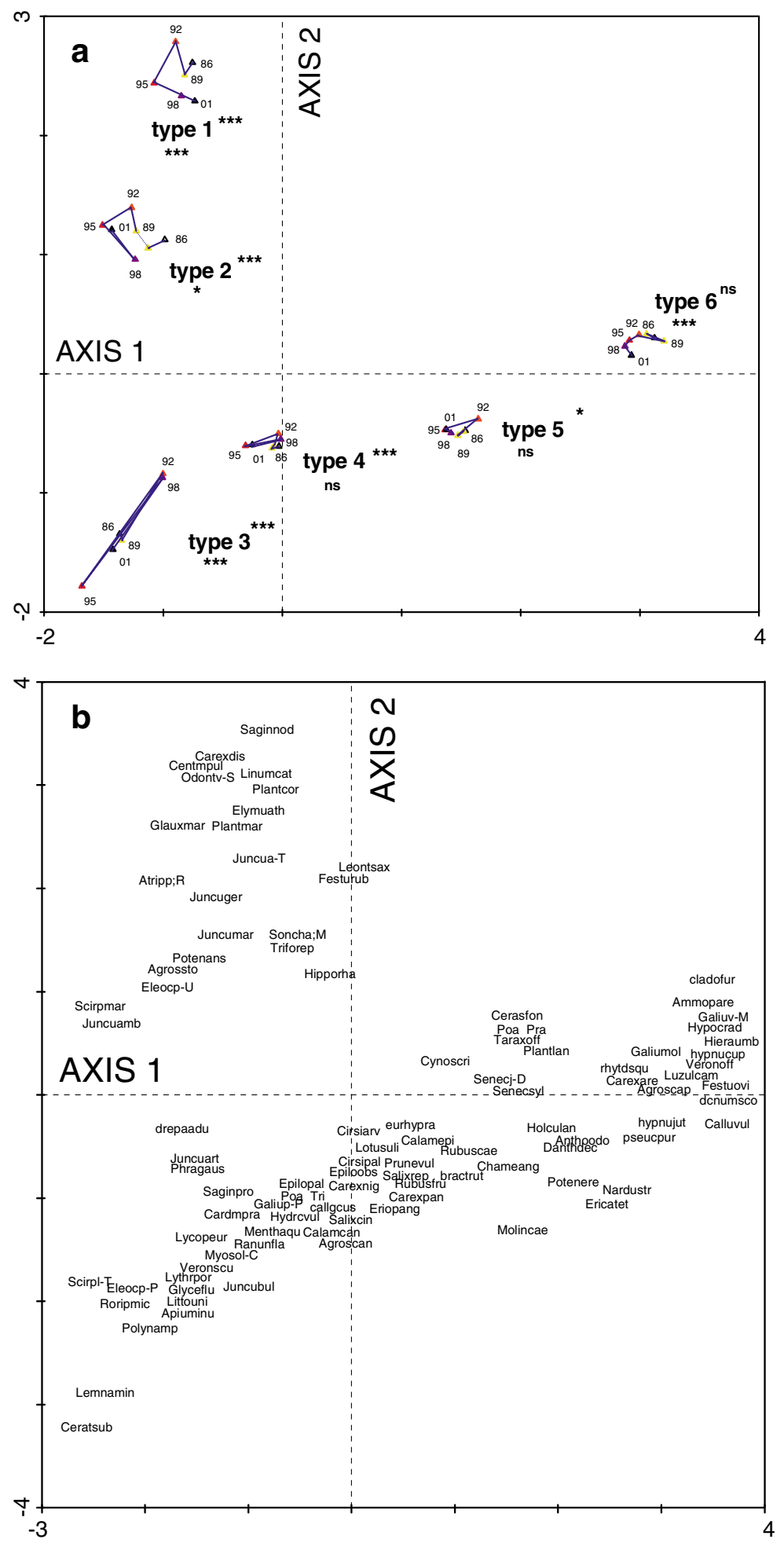

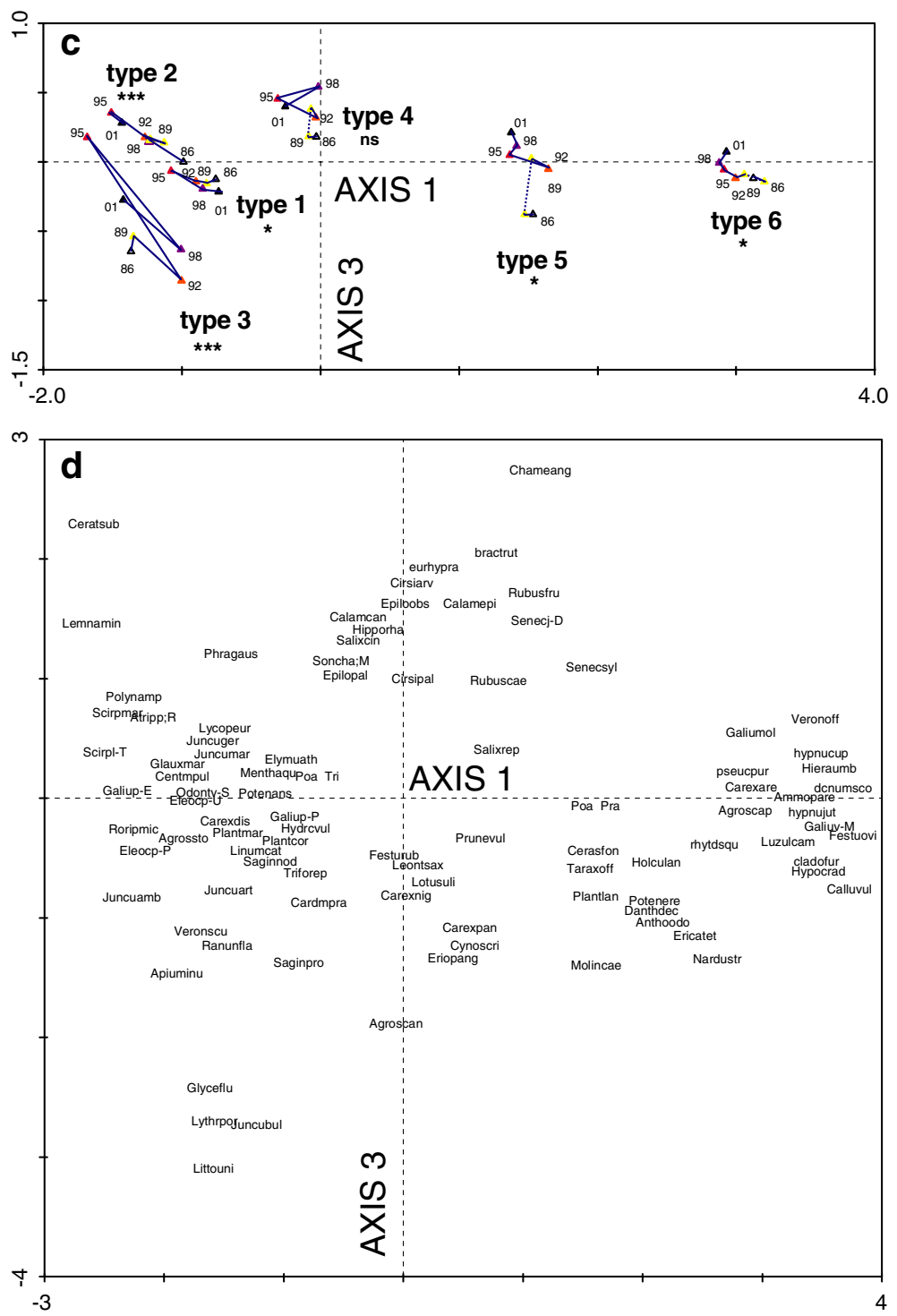

obvious interpretation for the species' positions on this axis, and it was therefore disregarded in subsequent analyses.

The position of the average sample scores in Fig. 2a and $\mathrm{c}$ shows that the temporal change has been small compared to the spatial variation. Moreover there are no very clear temporal trends. The temporal variation seems to be oscillatory rather than monotonous, with the possible exception of the third axis where a general trend can be observed towards higher values in the course of time (Fig. 2c). 
Fig. 2 Biplot resulting from DCA using all plot/year combinations. Detrending by 2nd order polynomials. Number of species: 276 , number of samples: 386 . Eigenvalues: $\lambda_{1}=0.708, \lambda_{2}=0.612$, $\lambda_{3}=0.457, \lambda_{4}=0.302$, sum of all eigenvalues $\Sigma \lambda=12.750$; the first three axes therefore represent $14 \%$ of the total variance in the species data. Species whose weight is less than $5 \%$ of the maximum species weight are not displayed, see Electronic Supplementary Material 3 for an explanation of the abbreviated species names. Explanation of type numbers: 1 sandy salt marsh, 2 clayey salt marsh, 3 dune slacks and pools incl. their shores, 4 dune shrub, 5 dune heath, 6 'grey' dunes. Year numbers 1986-2001 are indicated by their last two digits. a Axes 1 and 2, mean sample scores per plot/year combination, lines connect the values per type over time. The types where extra plots were installed in 1989 are displayed twice for that year, with and without the extra plots, and connected by a dashed line. The significance of the temporal changes determined by REML is indicated to the right of each type number for the first axis and below each type number for the second axis $(* * * P<0.001$, ** $P<$ 0.01 , ${ }^{*} P<0.05$, ns: $\left.P>0.05\right)$. See Table 1 for the significance of the linear trend. b Axes 1 and 2 , species. The score of each species is in the center of its abbreviated name but the position of some of the species has been slightly shifted for the sake of readability. c Axes 1 and 3, mean sample scores per plot/year combination. The significance of the temporal change on the third axis is indicated below each type number. d Axes 1 and 3, species

\subsection{Magnitude and significance of the temporal change}

Table 1 shows the significance of both the linear trend (as determined by a t-test on the regression coefficient of year number), and the overall temporal effect (as determined by REML and its corresponding Wald test; cf. Engel 1990). In both cases the effect of spatial variation was accounted for (by incorporating each plot as an extra variable in the linear regression or as a 'random' variable in REML). The overall temporal effect (whose significance levels are indicated in Fig. 2) is significant $(P<0.05)$ for both the DCA axes and the diversity indicators, but a significant temporal trend is only present for the first axis (decreasing), the third axis (increasing) and the number of species (decreasing). If the sample scores per type are considered, the temporal variation is very small (and statistically significant in only one or two of the directions) for the dry types 4, 5 and 6. For the wet types 1,2 and 3 this variation is larger (and significant in all directions), but often of an oscillatory nature as shown by the nonsignificant linear trend.

Both diversity indicators have a downward trend that occurs in all types (Table 1), however this trend is significant $(P<0.05)$ in a few cases only. By far the largest change occurred in type 2 (clayey salt marsh), where an average (and statistically significant) loss of 6.5 species per plot occurred since the start of the observations.

\subsection{Effect of soil subsidence}

Before testing the full model depicted in Fig. 1, the single relations (indicated by drawn arrows in Fig. 1) were tested for their statistical significance. All these relations appeared to be significant $(P<0.01$; see Electronic Supplementary Material 6 for details).

In order to get a better separation of the effects of both weather-related variables, an additional model was tested where the axes were rotated to maximise the representation of the effect of either PLS or FF along a single axis. This was achieved 


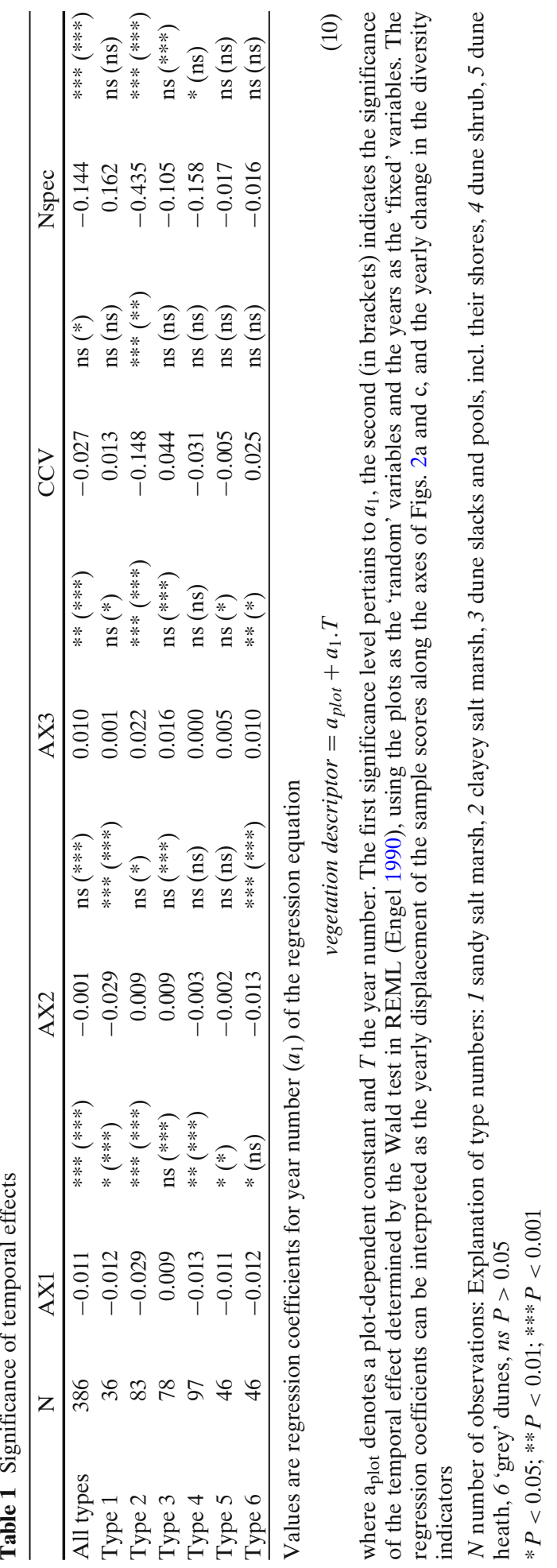


by executing two extra CCA analyses, in which either PLS or FF were used as the only explanatory variable, and using the first axis of these analyses. These new axes, which optimally represent the variation in the vegetation due to PLS and FF, respectively, are denoted AX-PLS and AX-FF. The result of this procedure is evaluated in Electronic Supplementary Material 6.

Next, the feasibility of soil subsidence as a cause for vegetation changes was assessed by back predicting the rate of soil subsidence from the vegetation. In order to make this back prediction, the vegetation descriptors were modelled as a function of the elevation in 1986, the soil subsidence, and the weather conditions, following Eq. 7. The soil chemical variables included in Fig. 3 were used as 'time independent variables' (Eq. 7). The contribution of soil subsidence and weather conditions to the explained variance was determined by omitting the terms for $\left(J-J_{0}\right)\left(D_{0}-D\right)$ and $X_{2}$, respectively, and by fitting the model with neither of these terms. The latter gives an estimate of the variance explained by the spatial pattern only (i.e., the soil chemistry and the elevation in 1986). The rate of soil subsidence was back predicted on the basis of Eq. 8, and compared to the 'true' subsidence values estimated by Eq. 6. The same procedure was also applied to phreatic level and flooding frequency, however without including the terms for soil chemistry, i.e. by replacing Eq. 3 by Eq. 2 .

Fig. 3 Correlation of environmental variables with sample scores depicted in Fig. 2. Note that the selection of the variables was done in CCA, but their effect is shown in the space of the DCA plot of Fig. 2; the coordinates of the heads of the arrows are the (scaled) correlation coefficients between the plot's scores on each axis, and the environmental variables. For the sake of comparison mean sample scores per type have been added. a Axis 1 and 2, b axis 1 and 3. Explanation of symbols: PLS phreatic level in spring (in $\mathrm{m}$ below soil surface so higher values indicate drier circumstances), $F F$ flooding frequency, $\mathrm{Ca}, \mathrm{Mg}$, Ntot soil total contents of $\mathrm{Ca}, \mathrm{Mg}$ and $\mathrm{N}$, respectively, $p H$ soil $\mathrm{pH}$ in water extract, explanation of type numbers in Fig. 2
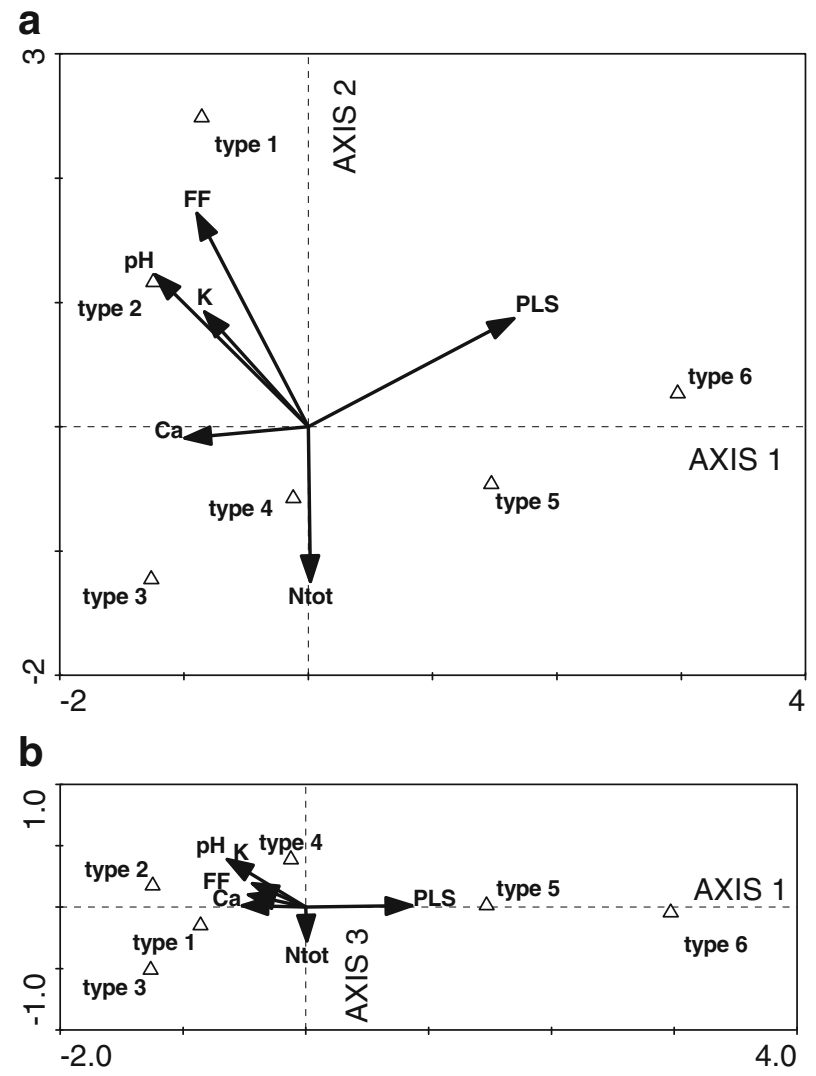
The result of the above analysis is given in Table 2. When accounting for the effect of fluctuations in net precipitation there appear to be significant effects of soil subsidence on the sample scores on AX3, on AX-PLS, and on the conservancy value; and when accounting for the effect of fluctuations in sea level regime there appear to be significant effects of soil subsidence on the flooding frequency, and on the sample scores on AX1, on AX-PLS and on AX-FF.

In Table 3 the back predicted soil subsidence rates are compared to the 'true' rates. This Table should be read as follows: the figures are the ratios between the back predicted and the 'true' rates, and their $99 \%$ confidence limits. If 0 is inside the range of the confidence limits for a given vegetation descriptor ('Y variable'), the effect of soil subsidence on that descriptor is not significant. If +1 is inside this range, the change in this descriptor is consistent with its relation with elevation in

Table 2 Effects of soil subsidence on phreatic level (PLS), flooding frequency (FF), DCA (AX1...3) and CCA axes (AX-PLS and AX-FF), conservancy value (CCV) and number of species (Nspec), after accounting for effects of fluctuations in net precipitation $\left(\mathrm{P}_{\text {net }}\right)$ and sea level regime $\left(\mathrm{FF}_{2}\right)$, following Eq. 7

\begin{tabular}{|c|c|c|c|c|c|c|c|c|}
\hline \multirow{3}{*}{$\begin{array}{l}\text { Term in } \\
\text { Vegetation } \\
\text { descriptor }\end{array}$} & \multirow{3}{*}{$\begin{array}{l}\text { Eq. } 7 \rightarrow \\
\\
\text { Weather- } \\
\text { related } \\
\text { variable }\left(\mathrm{X}_{2}\right) \\
\end{array}$} & \multirow{3}{*}{$\begin{array}{l}\text { Full model } \\
\text { All terms } \\
\text { var. expl. }\end{array}$} & \multirow{2}{*}{\multicolumn{2}{|c|}{$\begin{array}{l}\text { Soil subsidence } \\
\frac{\left(J-J_{0}\right)\left(D_{0}-D\right)}{}\end{array}$}} & \multirow{2}{*}{\multicolumn{2}{|c|}{$\begin{array}{l}\text { Weather } \\
X_{2}\end{array}$}} & \multirow{2}{*}{\multicolumn{2}{|c|}{$\begin{array}{l}\text { Spatial pattern } \\
\text { in } 1986 \\
\mathrm{Z}_{0}+\mathrm{f} \text { (time- } \\
\text { independent } \\
\text { variables) }\end{array}$}} \\
\hline & & & & & & & & \\
\hline & & & var. expl. & $P$ & var. expl. & $P$ & var. expl. & $\mathrm{P}^{\mathrm{a}}$ \\
\hline PLS & $\mathrm{P}_{\text {net }}$ & 40.9 & 0.0 & 0 & 2.4 & -3 & 38.5 & 3 \\
\hline AX1 & $P_{\text {net }}$ & 69.7 & 0.0 & 0 & 0.1 & 0 & 69.6 & 3 \\
\hline $\mathrm{AX} 2$ & $P_{\text {net }}$ & 45.3 & 0.1 & 0 & 0.0 & 0 & 45.3 & 2 \\
\hline AX3 & $P_{\text {net }}$ & 22.4 & 3.7 & 3 & 0.0 & 0 & 18.5 & 3 \\
\hline AX-PLS & $P_{\text {net }}$ & 58.9 & 1.4 & -3 & 0.0 & 0 & 57.0 & 3 \\
\hline AX-FF & $P_{\text {net }}$ & 68.7 & 0.0 & 0 & 0.0 & 0 & 68.7 & -3 \\
\hline $\mathrm{CCV}$ & $P_{\text {net }}$ & 27.7 & 3.8 & -3 & 0.8 & 1 & 24.1 & -3 \\
\hline Nspec & $P_{\text {net }}$ & 23.6 & 0.0 & 0 & 0.5 & 0 & 22.3 & 3 \\
\hline $\mathrm{FF}$ & $\mathrm{FF}_{2}$ & 95.4 & 7.0 & 3 & 6.5 & 3 & 84.7 & -3 \\
\hline $\mathrm{AX} 1$ & $\mathrm{FF}_{2}$ & 75.2 & 1.0 & -2 & 0.2 & 0 & 74.3 & 3 \\
\hline $\mathrm{AX} 2$ & $\mathrm{FF}_{2}$ & 61.3 & 0.0 & 0 & 0.2 & 0 & 61.4 & 0 \\
\hline AX3 & $\mathrm{FF}_{2}$ & 39.5 & 1.1 & 0 & 0.0 & 0 & 38.8 & -3 \\
\hline AX-PLS & $\mathrm{FF}_{2}$ & 73.1 & 2.5 & -3 & 0.0 & 0 & 70.7 & 3 \\
\hline AX-FF & $\mathrm{FF}_{2}$ & 72.5 & 2.4 & 3 & 1.1 & 2 & 69.8 & -3 \\
\hline $\mathrm{CCV}$ & $\mathrm{FF}_{2}$ & 43.8 & 1.0 & 0 & 0.0 & 0 & 43.0 & 1 \\
\hline Nspec & $\mathrm{FF}_{2}$ & 42.1 & 0.2 & 0 & 0.0 & 0 & 42.3 & 3 \\
\hline
\end{tabular}

Explained variances relate to Eq. 7 ('full model'), the loss of explained variance when dropping the third ('soil subsidence'), or the fourth term ('weather'), and a model without both these terms ('spatial pattern in 1986'). The absolute value of $P$ is the significance of each regression coefficient in the full model of Eq. 7 (3: $P<0.001,2: P<0.01,1: P<0.05,0: P>0.05$ ), the sign of $P$ is the sign of the regression coefficient. The plots that are inaccessible for seawater have been excluded from the determination of the effects of $\mathrm{FF}_{2}$. Numbers of observations: 386 when accounting for $\mathrm{P}_{\text {net }}$ and 165 when accounting for $\mathrm{FF}_{2}$

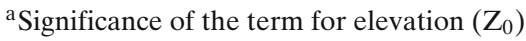


Table 3 Ratio of back predicted and 'true' soil subsidence rate

Back predicted values result from Eq. 8, the 'true' value $\left(-3.09523 \mathrm{E}-06 \mathrm{y}^{-1}\right)$ from

Eq. 6. 'Lower' and 'upper' limit are the $99 \%$ confidence limits of the estimate determined according to Fieller's theorem. The plots that are inaccessible for seawater have been excluded from the determination of the effects of $\mathrm{FF}_{2}$

${ }^{a}$ No back prediction because the effect of elevation in 1986 is not significant. See text for further explanation

\begin{tabular}{llccc}
\hline Y & Weather-related & \multicolumn{3}{c}{ Backpredicted/'true' soil subsidence } \\
\cline { 3 - 5 } variable & variable & Lower limit & Estimate & Upper limit \\
\hline PLS & $\mathrm{P}_{\text {net }}$ & -1.78 & -0.50 & 0.81 \\
AX1 & $\mathrm{P}_{\text {net }}$ & -1.12 & 0.19 & 1.41 \\
AX2 & $\mathrm{P}_{\text {net }}$ & -4.96 & 2.55 & 13.05 \\
AX3 & $\mathrm{P}_{\text {net }}$ & -26.95 & -7.63 & -2.46 \\
AX-PLS & $\mathrm{P}_{\text {net }}$ & 0.68 & 2.12 & 3.61 \\
AX-FF & $\mathrm{P}_{\text {net }}$ & -4.66 & 1.64 & 7.87 \\
CCV & $\mathrm{P}_{\text {net }}$ & -27.30 & -7.93 & -2.72 \\
Nspec & $\mathrm{P}_{\text {net }}$ & -1.88 & 0.77 & 3.16 \\
FF & $\mathrm{FF}_{2}$ & 1.28 & 1.56 & 1.85 \\
AX1 & $\mathrm{FF}_{2}$ & 0.03 & 0.53 & 1.06 \\
AX2 & $\mathrm{FF}_{2}$ & $-\mathrm{a}$ & $-\mathrm{a}$ & $-\mathrm{a}$ \\
AX3 & $\mathrm{FF}_{2}$ & -0.56 & 1.62 & 5.57 \\
AX-PLS & $\mathrm{FF}_{2}$ & 0.32 & 0.93 & 1.59 \\
AX-FF & $\mathrm{FF}_{2}$ & 0.50 & 1.50 & 2.75 \\
CCV & $\mathrm{FF}_{2}$ & -0.98 & 2.66 & 277.12 \\
Nspec & $\mathrm{FF}_{2}$ & -0.60 & 0.52 & 1.72 \\
\hline & & & &
\end{tabular}

1986 and the soil subsidence after that date. If the number in the column 'estimate' is above +1 , the vegetation has changed more than expected on the basis of the soil subsidence; if it is between 0 and +1 , the vegetation has changed less than expected on the basis of the soil subsidence. If the 'estimate' is negative (and in particular, if the 'upper limit' is negative), a rise in elevation has to be hypothesized to explain the observed vegetation change.

Out of the variables with a significant effect, only AX-PLS (when accounting for the effect of either phreatic level or sea level), and AX1 and AX-FF (when accounting for the effect of sea level) yield back predictions of the soil subsidence that are inside the expected range (i.e., +1 is inside the range in Table 3 , but 0 is outside this range). For phreatic level the effect of soil subsidence is not significant, but the back predicted soil subsidence is only slightly below the 'true' value. For flooding frequency the back predicted soil subsidence is slightly above the 'true' value. However, large discrepancies are found for the effects of soil subsidence on the third axis and on the conservancy values. Here the ratio of the back predicted and the 'true' soil subsidence is negative, i.e. the elevation is expected to increase instead of to decrease. Apparently both these variables changed over time, but the direction of this change is the opposite of the direction expected on the basis of soil subsidence and their relation with the elevation in 1986.

Table 4 gives the percentages variance in the fitted values that are uniquely due to soil subsidence, weather conditions, and the spatial pattern at the start of the monitoring, respectively. By far the largest part of total variance is due to the spatial pattern. Of the vegetation descriptors a maximum of c. $3 \%$ of the variance in the fitted values is due to soil subsidence, and a maximum of c. $2 \%$ is due to weather conditions. For the abiotic conditions (PLS and FF) higher values were found, up to c. $7 \%$ for both weather conditions and soil subsidence. To judge by the percentages explained variance, the overall changes have been small and soil subsidence and weather conditions have contributed to these changes in about equal amounts. 
Table 4 Percentage variance in the fitted values that is uniquely due to soil subsidence, weather conditions and spatial pattern, for those variables that yield a back predicted soil subsidence rate that is in the same order of magnitude as the 'true' rate (irrespective of the significance of the effects)

\begin{tabular}{llllc}
\hline Variable & $\begin{array}{l}\text { Weather } \\
\text { represented by: }\end{array}$ & \multicolumn{3}{l}{$\begin{array}{l}\text { Percentage variance in the fitted } \\
\text { values that is uniquely due to: }\end{array}$} \\
\cline { 3 - 5 } & & $\begin{array}{l}\text { Soil } \\
\text { subs }(\%)\end{array}$ & $\begin{array}{l}\text { Weather } \\
(\%)\end{array}$ & $\begin{array}{c}\text { Spatial } \\
\text { pattern }(\%)\end{array}$ \\
\hline PLS & $\mathrm{P}_{\text {net }}$ & 0.0 & 5.8 & 94.2 \\
AX1 & $\mathrm{P}_{\text {net }}$ & 0.0 & 0.1 & 99.8 \\
AX2 & $\mathrm{P}_{\text {net }}$ & 0.1 & 0.0 & 100.0 \\
AX-PLS & $\mathrm{P}_{\text {net }}$ & 2.4 & 0.0 & 96.8 \\
AX-FF & $\mathrm{P}_{\text {net }}$ & 0.0 & 0.0 & 100.0 \\
Nspec & $\mathrm{P}_{\text {net }}$ & 0.0 & 2.3 & 94.5 \\
FF & $\mathrm{FF}_{2}$ & 7.3 & 6.9 & 88.8 \\
AX1 & $\mathrm{FF}_{2}$ & 1.3 & 0.2 & 98.8 \\
AX3 & $\mathrm{FF}_{2}$ & 2.7 & 0.0 & 98.3 \\
AX-PLS & $\mathrm{FF}_{2}$ & 3.4 & 0.0 & 96.6 \\
AX-FF & $\mathrm{FF}_{2}$ & 3.4 & 1.5 & 96.3 \\
CCV & $\mathrm{FF}_{2}$ & 2.3 & 0.0 & 98.0 \\
Nspec & $\mathrm{FF}_{2}$ & 0.4 & 0.0 & 100.0 \\
\hline
\end{tabular}

\subsection{Scenarios}

Figures 4 and 5 show the expected effect of combinations of soil subsidence and climate change until 2020 and 2100 based on the fitted parameters of Eq. 9 and the scenarios described above. For 2020, this effect is shown for soil subsidence only, and in combination with climate change (Fig. 4a), and for 2100 it is shown for soil subsidence plus each separate component of climate change (increase of precipitation, increase of storm frequency, and rise of mean sea level), and for their combination (Fig. 4b). The expected change due to soil subsidence until 2020 is rather small, and similar in magnitude to the change occurring over one or two of the 3-year intervals before 2001. Climate will add an extra change that is in the same direction and in the same order of magnitude as the change due to soil subsidence. By 2100 large changes are expected that are mainly due to mean sea level rise. These effects far exceed the effects of soil subsidence over the period 1986-2001, although their direction is the same. In general, climate change will amplify the effects of soil subsidence, i.e. force the salt marsh vegetation in the direction of pioneer stages, and the dune vegetation in the direction of wet dune valleys (this can be inferred by overlaying Figs. 4 and 2b). Note that along the first axis the trajectories between 2001 and 2100 run in the same direction for all types, i.e. all types will become wetter, however along the second axis the directions are opposite for types 1-2 and

Fig. 4 Modelled values of mean scores per type on the first and second axis. a Until 2020, b until 2100. The closed symbols are the expected values for 1986 (circle) and subsequent 3-year intervals until 2001 (triangles), the open symbols are the extrapolated values under the following scenarios: $S$ soil subsidence + sea level rise and increases in storm frequency and net precipitation (a and $\mathbf{b})$, $Z$ only soil subsidence (a), $F$ increase in storm frequency only (b), $P$ increase in net precipitation only (b). Note that this figure is comparable to Fig. 2, however for the trajectories 1986-2001 Fig. 2 represents observed values and this figure represents fitted values. For the period 19862001 (the closed symbols) these are determined on the basis of the actual elevation of each plot, net precipitation and flooding frequency in those years. The values after 2001 are determined on the basis of a linear increase of soil subsidence until 2020, and linear increases of mean sea level, flooding frequency and net precipitation until 2100. For explanation of type numbers see Fig. 2 
a

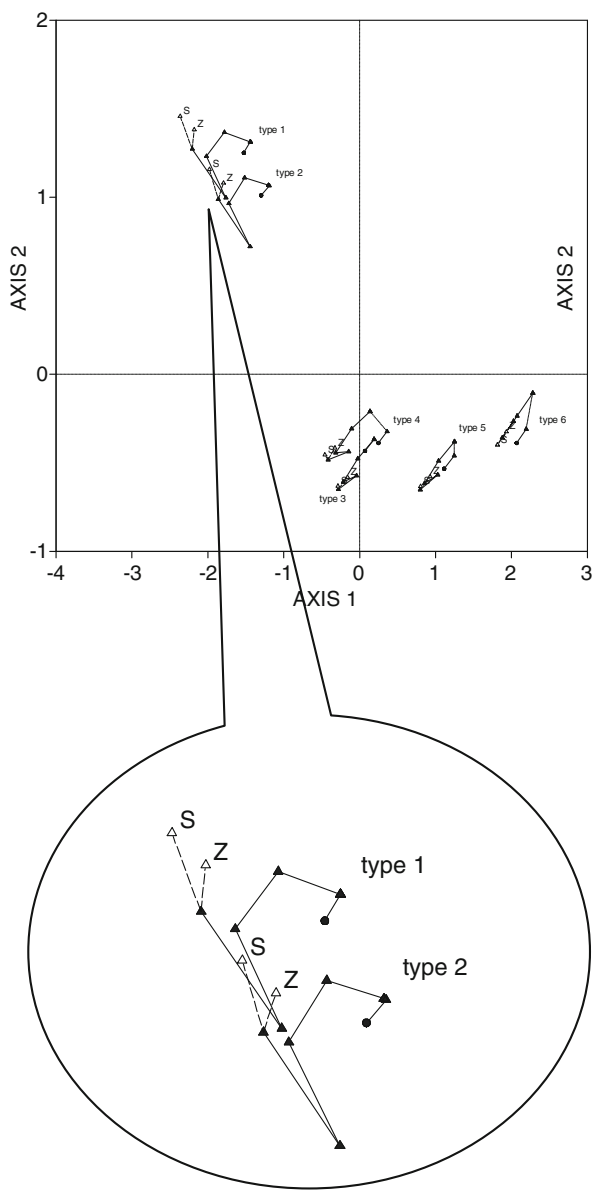

b

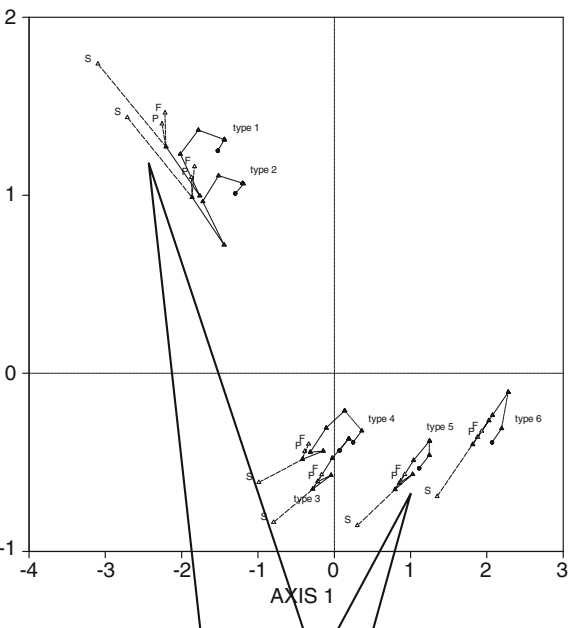

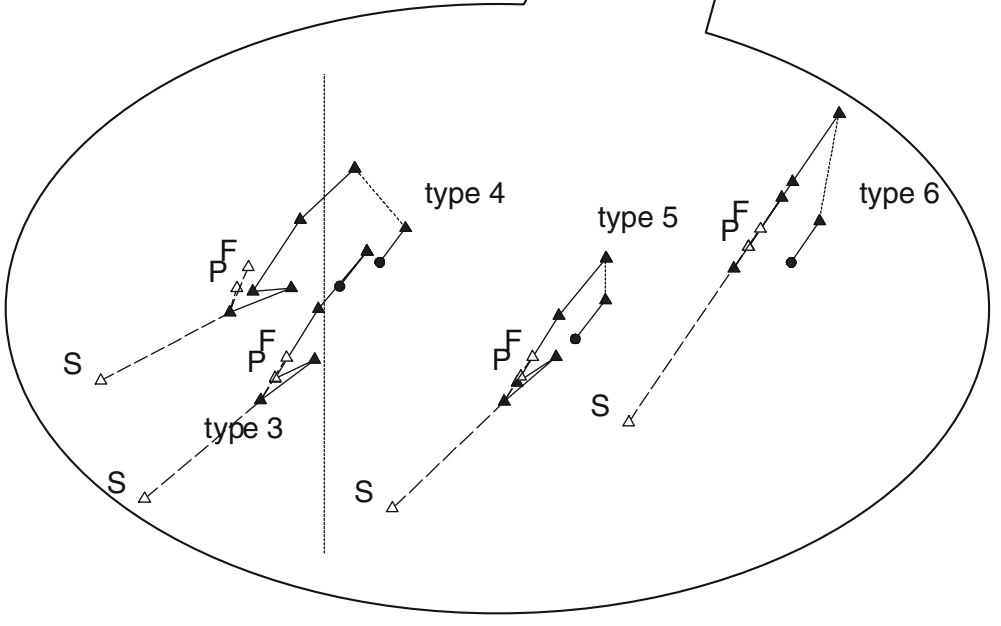


Fig. 5 Modelled values of mean diversity indicators. $\mathbf{a} \mathrm{CCV}, \mathbf{b}$ number of species. Values are determined as in Fig. 4, the scenario comprises the sum of soil subsidence, sea level rise and increases in storm frequency and net precipitation. Note that the $\mathrm{X}$-axis is shortened between 2020 and 2100. For explanation of type numbers see Fig. 2. Scaling of CCV: $<12$, vegetation with little conservancy value, probably consisting of few and common species; 12-16, vegetation which may have some conservancy value, rare or Red List species may occur; $>16$, vegetation with a high conservancy value, and a high probability for Red List species to occur a
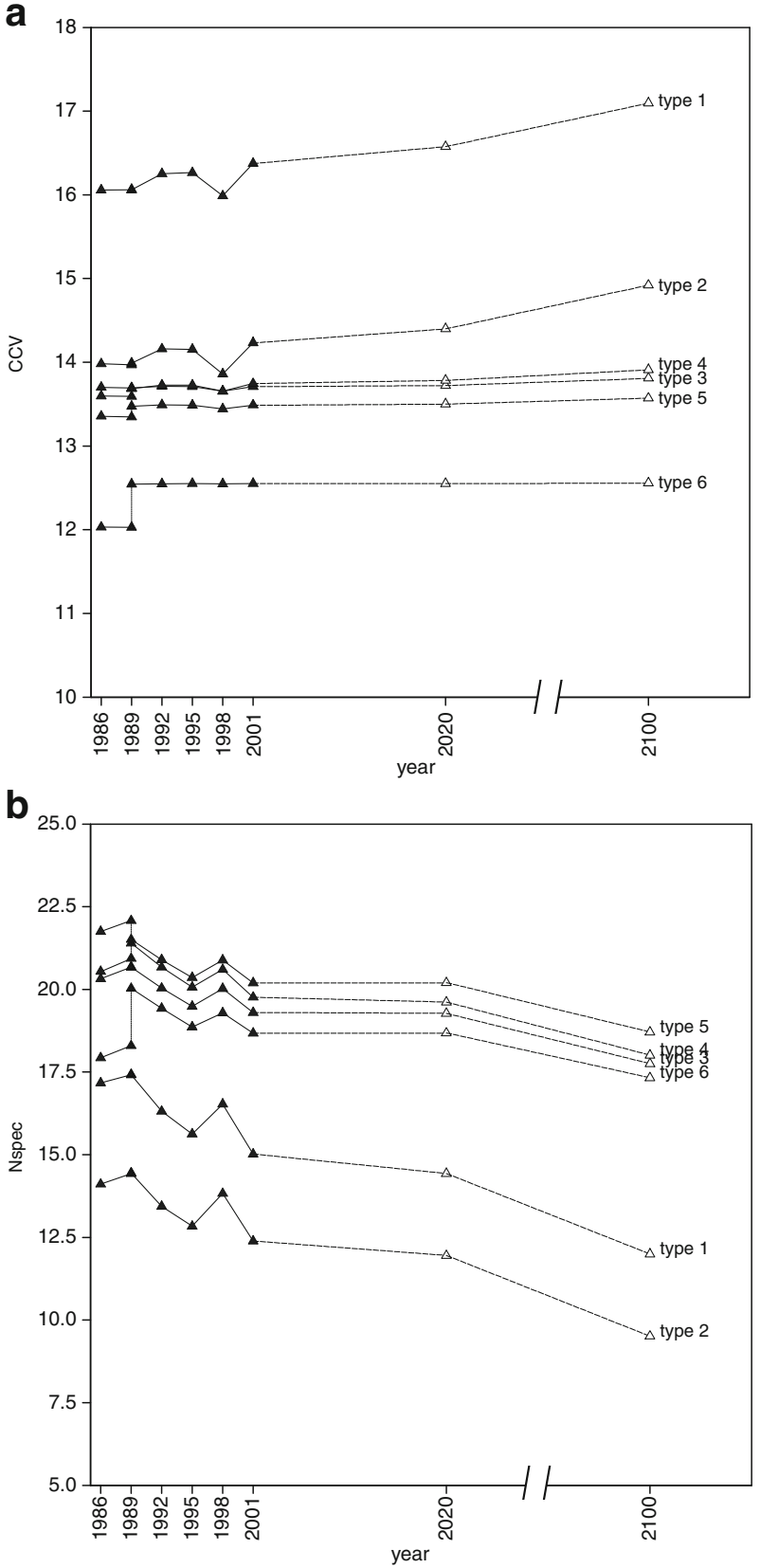

3-6, respectively, i.e. types 1 and 2 have an increasing saltwater influence while the other types have an increasing freshwater influence. The above changes may be slightly modified by the balance between the increase in storm frequency and the increase in net precipitation. A loss of species is expected, however the CCV is expected to remain virtually unchanged or even increase (Fig. 5). 


\section{Discussion and conclusions}

Our analyses show that only small changes in the vegetation have occurred during the 15-year observation period in spite of substantial soil subsidence. These changes are partly of an oscillatory nature, but linear trends could also be detected. There has been some loss of diversity, but in general this loss has been small and in many cases non-significant. An interesting question is whether a loss of diversity is attributable to soil subsidence and thus, whether climate change is expected to cause a loss of diversity. In general this question has to be answered negatively. Table 2 shows that the effect of soil subsidence on the number of species is nonsignificant and that its effect on the CCV is significant, however the actual change in CCV (a decrease) is the opposite of the change expected on the basis of its relation with elevation (an increase) (Table 3). It is therefore improbable that the loss of diversity is actually caused by soil subsidence. Thereby it also becomes improbable that sea level rise will lead to a loss of diversity.

Despite the absence of a clear effect on diversity, soil subsidence did most probably cause changes in the vegetation. There is a significant effect of soil subsidence on the score on the first axis when accounting for the effect of flooding frequency; this effect is a shift towards lower values, i.e. towards species of wetter habitats. No significant effects of soil subsidence on the second axis were found. This is not surprising as the sample scores on this axis did not have a significant temporal trend (Table 1), i.e. there was no trend in the direction of species indicative for either sea water of freshwater influence.

The scenario study shows that no large effects are to be expected of the soil subsidence that is still to occur until the gas field is completely drained. However, these effects will be much amplified by the sea level rise that is expected during the present century. In general we expect all habitats to become wetter, however in the saltmarsh habitats the influence of seawater will increase while in other habitats the influence of freshwater will increase (Fig. 4). In the model this is caused by the fact that new values for $\mathrm{Z}$ (elevation) are generated by simply subtracting the expected sea level rise from the actual $\mathrm{Z}$ values, and this is justified by the expectation that a freshwater lens will keep floating on the seawater (Noest 1991).

Our study indicates a loss of species due to climate change, but little change in conservancy value or even an increase (Fig. 5). This means that mostly common species are expected to be lost, while the rarer ones (e.g. those of extreme habitats, usually the ones with a high dispersal capability and resistance to increased disturbance) may persist. The expected change is due to sea level rise for the far larger part, but is slightly modified by increases in net precipitation or storm frequency.

It should be realised that the magnitude of future change will be under-estimated if other phenomena than the ones included here play a significant role. This may be the case for salt-spray which will increase as storm frequency increases, and may affect vegetation (Vertegaal 1999). Also, salinisation of pools may occur as sea-level rises, however in our case this is improbable as precipitation also increases and thereby the thickness of the layer of freshwater floating on top of the seawater will increase. On the other hand our method may also lead to over-estimation of the effects of climate change. As flooding frequency increases, sedimentation will also increase and partly compensate both soil subsidence and sea level rise (Morris et al. 2002; Dijkema et al. 2005). Also, other factors than soil subsidence and climate change 
are not accounted for in the scenario predictions, and these may partly outweigh the factors that are accounted for. This is demonstrated by the change in CCV over time, which is expected to remain constant or increase in the prediction (Fig. 5), while in fact it decreased during the observation period (Table 1). However, in general the effects of climate change predicted in our study are comparable to those predicted for similar coastal habitats by Noest (1991) and Vestergaard (1997).

The changes in CCV and in the sample score on the third axis have a significant relation with soil subsidence (Table 2), but their regression coefficients indicate that soil subsidence cannot be the causal factor. As positive values on the third axis are related to highly productive species (cf. Figs. 2c and d), it is tempting to ascribe the shift along the third axis to the general increase in nutrient availability that has been observed by many authors in the dunes of both The Netherlands and adjacent countries (Veer 1997; Kooijman et al. 1998; Ketner-Oostra and Sýkora 2004; Jones et al. 2004; Provoost et al. 2004; Jones et al. 2008). The denser vegetation that resulted from this change has often outcompeted the rarer, less productive species, which would explain the general loss of conservancy value. This change, which has occurred over the past two to three decades, is usually ascribed to a combination of atmospheric deposition of nitrogen compounds, and a decreasing management intensity (e.g. by grazing, Aptroot et al. 2007). Also the collapse of the rabbit population in the same period might be a causal factor (Bijlsma 2004).

Tables 2 and 3 show that there are also significant effects of weather conditions. In contrast to effects of soil subsidence and the general trend towards eutrophication, which are monotonous trends, these effects are of an oscillatory nature. These effects are most prominent in type 3 (Table 1). This can be understood on the basis of the ecology of this type, which consists of wet dune slacks and shallow pools. Here, the number of species and the CCV run strongly anti-parallel to the precipitation, with maximum values following dry periods in 1992 and 1998, and a minimum value following an extremely wet period in 2001 (data not shown, cf. Van Dobben and Slim 2005). An obvious explanation is that the water level in spring is a key factor. In dry periods this level is low, leaving a broad shore area for germination of annual species, while in wet periods these areas are under water and therefore less rich in species during the summer (During 1980). However, the scenario study shows that the effects of increasing precipitation will be limited.

On the basis of the above observations it can be concluded that (a) the temporal change in the vegetation over a 15-year period has been small, and was due to a combination of weather fluctuations, soil subsidence and eutrophication; (b) these changes can partly be interpreted as a loss of diversity, but (c) the loss of diversity is probably due to eutrophication rather than to soil subsidence; and (d) in the next century vegetation is expected to strongly change as a result of sea level rise, (e) this change cannot be interpreted as a loss of diversity as it will mostly entail a decrease of common species but an increase of rare species of extreme habitats.

Acknowledgements This study was partly supported by the Nederlandse Aardolie Maatschappij BV (NAM). Thanks are due to Cajo ter Braak and to the 'Begeleidingscommissie Monitoring Bodemdaling Ameland' for fruitful discussions and comments on earlier versions of the manuscript, and to 'It Fryske Gea' for permission for fieldwork and assistance in the field. Jaap Wiertz provided the vegetation observations in 1989. The soil subsidence model described in Electronic Supplementary Material 2 was provided by NAM. 
Open Access This article is distributed under the terms of the Creative Commons Attribution Noncommercial License which permits any noncommercial use, distribution, and reproduction in any medium, provided the original author(s) and source are credited.

\section{References}

Aptroot A, Van Dobben HF, Slim PA, Olff H (2007) The role of cattle in maintaining plant species diversity in wet dune valleys. Biodivers Conserv 16:1541-1550

Bijlsma RG (2004) Long-term population trends of rabbits (Oryctolagus cuniculus) on Pleistocene sands in the central and northern Netherlands. Lutra 47:3-20

Church JA, Gregory JM, Huybrechts P, Kuhn M, Lambeck K, Nhuan MT, Qin D, Woodworth PL (2001) Changes in sea level. In: Houghton JT et al (eds) Climate change 2001: the scientific basis. Cambridge University Press, New York, pp 639-693

Dijkema KS, Wolff WJ (1983) Flora and vegetation of the Wadden sea islands and coastal areas. Stichting Veth, Leiden

Dijkema KS, Van Duin WE, Van Dobben HF (2005) Kweldervegetatie op Ameland: effecten van veranderingen in de maaiveldhoogte van Nieuwlandsrijd en De Hon. In: Begeleidingscommissie Monitoring Bodemdaling Ameland (ed) Monitoring effecten van bodemdaling op AmelandOost, pp 1-97

Dijkema KS, Van Duin WE, Meesters HWG, Zuur AF, Ieno EN, Smith GM (2007) Sea level change and salt marshes in the Wadden Sea: a time series analysis. In: Zuur AF et al (eds) Analysing ecological data. Springer Science, New York, pp 601-614

During HJ (1980) Life forms and life strategies in Nanocyperion communities from the Netherlands Frisian islands. Acta Bot Neerl 29:483-496

Ellenberg H, Weber HE, Düll R, Wirth V, Werner W, Pauliszen D (1991) Zeigerwerte von Pflanzen in Mitteleuropa. Scr Geobot 18:1-248

Engel B (1990) The analysis of unbalanced linear models with variance components. Stat Neerl 44:195-219

Eysink WD, Dijkema KS, Van Dobben HF, Slim PA, Smit CJ, Sanders ME, Schouwenberg EPAG, Wiertz J, De Vlas J (2000) Monitoring effecten bodemdaling op Ameland-Oost: evaluatie na 13 jaar gaswinning: samenvatting. Report Alterra/WL|Delft Hydraulics

Finney DJ (1971) Probit analysis, 3rd edn. Cambridge University Press, Cambridge

Hertog AJ, Rijken M (1996) Geautomatiseerde bepaling van natuurbehoudswaarde in vegetatieopnamen. Report provincie Gelderland

Hill MO (1979) TWINSPAN - a FORTRAN program for arranging multivariate data in an ordered two-way table by classification of the individuals and attributes. Cornell University, Ithaca

Huston MA (1994) Biological diversity: the coexistence of species on changing landscapes. Cambridge University Press

IUCN (2001) IUCN red list categories: version 3.1. Prepared by the IUCN Species Survival Commission. IUCN, Gland

Jones MLM, Wallace HL, Norris D, Brittain SA, Haria S, Jones RE, Rhind PM, Reynolds BR, Emmett BA (2004) Changes in vegetation and soil characteristics in coastal sand dunes along a gradient of atmospheric nitrogen deposition. Plant Biol 6:598-605

Jones, MLM, Sowerby A, Williams DL, Jones RE (2008) Factors controlling soil development in sand dunes: evidence from a coastal dune soil chronosequence. Plant Soil 307:219-234

Jongman RHG, Ter Braak CJF, Van Tongeren OFR (1995) Data analysis in community and landscape ecology. Cambridge University Press, Cambridge

Ketner-Oostra R, Sýkora KV (2000) Vegetation succession and lichen diversity on dry coastal calcium-poor dunes and the impact of management experiments. J Coast Conserv 6:191-206

Ketner-Oostra R, Sýkora KV (2004) Decline of lichen-diversity in calcium-poor coastal dune vegetation since the 1970s, related to grass and moss encroachment. Phytocoenologia 34:521-549

Kooijman AM, Dopheide JCR, Sevink J, Takken I, Verstraten JM (1998) Nutrient limitations and their implications on the effects of atmospheric deposition in coastal dunes; lime-poor and limerich sites in the Netherlands. J Ecol 86:511-526

Lowe JA, Gregory JM, Flather, RA (2001) Changes in the occurrence of storm surges around the United Kingdom under a future climate scenario using a dynamic storm surge model driven by the Hadley Centre climate models. Clim Dyn 18:179-188 
Marquenie JM, Doornhof D (2005) Bodemdaling en gaswinning. In: Begeleidingscommissie Monitoring Bodemdaling Ameland (ed) Monitoring effecten van bodemdaling op Ameland-Oost, pp 1-9

Morris JT, Sundareshwar PV, Nietch CT, Kjerfve B, Cahoon DR (2002) Responses of coastal wetlands to rising sea level. Ecology 83:2869-2877

Noest V (1991) Simulated impact of sea level rise on phreatic level and vegetation of dune slacks in the Voorne dune area (The Netherlands). Landscape Ecology 6:89-97

Oberdorfer E (1979) Pflanzensoziologische Exkursionsflora. Ulmer, Stuttgart

Payne RW, Harding SA, Murray DA, Soutar DM, Baird DB, Glaser AI, Channing IC, Welham SJ, Gilmour AR, Thompson R, Webster R (2008) GenStat ${ }^{\circledR}$ release 11 reference manual. VSN International, Hemel Hempstead

Provoost S, Ampe C, Bonte D, Cosyns E, Hoffmann M (2004) Ecology, management and monitoring of grey dunes in Flanders. J Coast Conserv 10:33-42

Robinson DL (1987) Estimation and use of variance components. Statistician 36:3-14

Sanders ME, Slim PA, Van Dobben HF, Wegman RMA, Schouwenberg EPAG (2004) Effecten van eilandvarianten in de Noordzee op de ecologie van strand en duin. Alterra Report 1092

Senior CA, Jones RG, Lowe JA, Durman CF, Hudson D (2002) Predictions of extreme precipitation and sea-level rise under climate change. Phil Trans R Soc London A 360:1301-1311

Siebel HN (1993) Indicatiegetallen van blad- en levermossen. IBN Report 47

Slim PA, Heuvelink GBM, Kuipers H, Dirkse GM, Van Dobben HF (2005) Vegetatiemonitoring en geostatistische vegetatiekartering duinvalleien Ameland-Oost. In: Begeleidingscommissie Monitoring Bodemdaling Ameland (ed): monitoring effecten van bodemdaling op AmelandOost, pp 1-74

Ter Braak CJF, Smilauer P (2002) CANOCO reference manual and Canodraw for windows user's guide: software for canonical community ordination (version 4.5). Microcomputer Power, Ithaca

Van der Meijden R, Weeda EJ, Holverda WJ, Hovenkamp PH (1990) Heukels' Flora van Nederland. Wolters-Noordhoff, Groningen

Van Dieren JW (1934) Organogene Dünenbildung, eine geomorphologische Analyse der westfrisischen Insel Terschelling mit pflanzensoziologischen Methoden. Nijhoff, Den Haag

Van Dobben HF, Slim PA (2005) Evaluation of changes in permanent plots in the dunes and upper salt marsh at Ameland East: ecological effects of gas extraction. In: Begeleidingscommissie Monitoring Bodemdaling Ameland (ed) Monitoring effecten van bodemdaling op AmelandOost, pp 1-36

Van Dobben HF, Ter Braak CJF (1998) Effects of atmospheric NH3 on epiphytic lichens in the Netherlands: the pitfalls of biological monitoring. Atmos Environ 32:551-557

Van Dobben H, Wamelink, W (2009) A Red-List-based biodiversity indicator and its application in model studies in the Netherlands. In: Hettelingh J-P et al (eds): Progress in the modelling of critical thresholds, impacts to plant species diversity and ecosystem services in Europe: CCE Status Report 2009. Coordination Centre for Effects, Bilthoven, pp 77-81

Veer MAC (1997) Nitrogen availability in relation to vegetation changes resulting from grassencroachment in Dutch dry dunes. J Coast Conserv 3:41-48

Vertegaal CTM (1999) Effecten van saltspray(reductie) op natuurwaarden in de duinen: literatuuroverzicht en analyse van leemten in kennis. Ministerie van Verkeer en Waterstaat,'sGravenhage

Vestergaard P (1997) Possible impact of sea-level rise on some habitat types at the Baltic coast of Denmark. Journal of Coastal Conservation 3:103-112

Wamelink GWW, Ter Braak CJF, Van Dobben HF (2003) Changes in large-scale patterns of plant biodiversity predicted from environmental economic scenarios. Landsc Ecol 18:513-527

Weeda EJ, Westra R, Westra C, Westra T (1985-1994) Nederlandse Oecologische Flora, vol 1-5. KNNV Uitgeverij, Utrecht 